\title{
Comparative Evaluation of the Bleaching Efficacy of Colgate Visible White, Close-Up Diamond Attraction Compared With Pola Office Plus
}

\author{
Anita Kalsi*, Saloni Gupta \\ Endodontics
}

Received: November 14, 2017; Published: November 30, 2017

*Corresponding author: Anita Kalsi, Endodontics

\begin{abstract}
Bleaching is very common and costly procedure for whitening of teeth. As the aesthetic concern of the patient's increases these days, the introduction of wide range of less costly whitening products in the market also increases which promises whitening in few applications.

Aim: The objective of this in vivo study is to check the bleaching efficacy of Colgate Visible White, Close-up Diamond Attraction compared with Pola Office Plus.

Materials \& Methods: 15 patients were selected and randomly divided into three groups according to whitening agents used. Each group contains five patients i.e. $\mathrm{n}=5$. The application time is as per recommended by the product instructions. For the evaluation of shade selection - color of both canines in upper jaw was evaluated visually before and after bleaching. Tooth shade was evaluated using VITA classical shade guide.
\end{abstract}

Results: After statistical analysis a significant difference was seen in shade change between pre and post treatment in each group. However, no significant difference was found between all the three groups.

Conclusion: Tooth whitening using minimally invasive techniques is enjoyable for the clinician and allows the patients to smile with confidence.

Keywords: Bleaching; Colgate visible white; Close up diamond attraction; Pola office plus

\section{Introduction}

Patients increasingly seek to have an attractive smile, as it is considered to be synonymous with health. This growing demand for an enhanced esthetic appearance has led to great development of bleaching products. The color of teeth is influenced by a combination of their intrinsic color and the presence of any extrinsic stains that may form on the tooth surface. Tooth discoloration can be treated professionally with in office or home bleaching. Pola Office+ is the advanced version of the well known in-office tooth-whitening system, Pola Office, which has been used successfully for several years. Pola office + contain desensitizing agents, such as potassium nitrate, to reduce postoperative sensitivities in vital teeth. Also, the whitening tooth pastes have gained in popularity for treating extrinsic stains. The effectiveness of toothpastes at reducing or removing extrinsic dental stain has improved with the introduction of more whitening toothpastes onto the market [1]. A key feature of whitening toothpastes is that they include proteolytic enzymes that remove extrinsic stains from teeth. It is claimed that some whitening toothpastes also remove pellicle (external membrane) from a tooth surface [2].

Apart from containing whitening agents, whitening toothpastes also commonly contain bicarbonates and fluoride to promote caries protection. In Turkey, it has been suggested that further clinical studies are required to help clinicians decide exactly which whitening toothpaste(s) to recommend to patients [3]. A cursory appraisal of the ingredients suggests that most whitening toothpastes are formulated to control extrinsic dental stain rather than to change the natural colour through a bleaching action [4]. The market continues to expand as more tooth whitening dentifrices become available and clearly it is important to evaluate these products. Many clinical techniques such as the Lobene Stain Index (1968) [5], the Shaw and Murray Stain Index (1977) [6], and the comparison of tooth colour with a Vita shade guide have been used to investigate the reduction of extrinsic staining of teeth. Many clinical studies into the whitening effect of dentifrices have 
been reported, with study periods differing from two weeks to six months [7].

\section{Aim of the Study}

The objective of this in vivo study is to check the bleaching efficacy of Colgate Visible White, Close-up Diamond Attraction compared with Pola Office Plus.

\section{Materials and Methods}

An initial sample of 15 patients aged from 18 to 30 years was selected from patients who came to our department for tooth bleaching. A randomized, single-blind (examiner-blinded) trial was conducted. The examiner and all staff were blind to the treatment assigned throughout the study. Study inclusion criteria (evaluated at a first examination) were as follows: age $\geq 18$ years, absence of gingival recession or restorations in upper-front teeth, good oral hygiene and gingival health, no previous tooth bleaching procedure, tooth shade of A2 or above on the Vita ClassiÊl Shade Guide scale (Vident, Brea, Calif, USA.) ordered by value, and, in the case of females, not being pregnant or in breast-feeding period. Subjects were excluded if they used tobacco products, had aesthetic restorations, which could become discolored, or were already taking chromogenic oral products, such as chlor hexidine, or medications that could stain the dentition. Before the bleaching treatments, baseline numerical shade values were obtained for central incisors and canines of both hemiarches in accordance with the Vita Classical Shade Guide (Figure 1 \& 2). Shade tabs were arranged in the sequence recommended by the manufacturer, assigning each tab with a number from 1 to 16 (B1, A1, B2, D2, A2, C1, C2, D4, Table 1: N Par Tests.
A3, D3, B3, A3.5, B4, C3, A4, C4). The shade was recorded by two independent examiners not otherwise involved in the study (K coefficient $=0.85$, standard error $=0.09$ ), who were blinded to the materials used. Group 1(n-5) patients were assigned Colgate visible white tooth paste. Group 2 (n-5) were assigned Close up diamond attraction toothpaste. Subjects were instructed to brush their teeth twice a day, in the morning after breakfast and in the evening before sleeping. Subjects were not given any instructions about drinking and eating, and were allowed to follow their previous patterns for these activities. In Group 3 (n-5) patients bleaching was performed by Pola office + . The dual-barrel syringe system of Pola Office+ always delivers a consistent mixture of freshly activated gel that can be easily applied with a fine applicator tip, even in hard-toreach areas .Excess gel was removed with a cotton pellet. A thin layer of gel was applied on the vestibular surface of the tooth. The gel was left on the tooth for eight minutes and then removed using a surgical aspirator tip. The application steps were repeated up to three times, so that the material is on the tooth for a maximum of four times for 8minutes (32minutes in total) in one session.

\section{Results}

Fifteen patients completed the study protocol, with a mean age of 23.8 years (range, 18-30 years). No adverse effects on soft tissue were reported by the patients or observed by the examiners. After statistical analysis, a significant difference was seen in shade change between pre and post treatment in each group. (Table $1 \& 2$ ) However, no significant differenc was found between all the three groups (Figure 1-4).

\begin{tabular}{|c|c|c|c|c|c|c|c|c|c|}
\hline \multicolumn{10}{|c|}{ Descriptive Statistics } \\
\hline Group & & $\mathbf{N}$ & Mean & Std.mean & Minimum & Maximum & Percentiles & & \\
\hline & & & & & & & $25^{\text {th }}$ & $50^{\text {th }}$ (Median $)$ & $75^{\text {th }}$ \\
\hline \multirow{2}{*}{1} & $\begin{array}{l}\text { Value of } \\
\text { shade pre }\end{array}$ & 5 & 11.20 & 1.304 & 9 & 12 & 10.00 & 12.00 & 12.00 \\
\hline & $\begin{array}{l}\text { Value of } \\
\text { shade pre }\end{array}$ & 5 & 6.6 & 2.191 & 5 & 6 & 5.00 & 5.00 & 9.00 \\
\hline \multirow{2}{*}{2} & $\begin{array}{l}\text { Value of } \\
\text { shade pre }\end{array}$ & 5 & 8.00 & 4.583 & 3 & 12 & 3.00 & 11.00 & 11.50 \\
\hline & $\begin{array}{c}\text { Value of } \\
\text { shade pre }\end{array}$ & 5 & 6.20 & 3.834 & 2 & 9 & 2.00 & 9.00 & 9.00 \\
\hline \multirow{2}{*}{3} & $\begin{array}{l}\text { Value of } \\
\text { shade pre }\end{array}$ & 5 & 10.6 & 4.393 & 3 & 14 & 7.00 & 12.00 & 13.50 \\
\hline & $\begin{array}{l}\text { Value of } \\
\text { shade pre }\end{array}$ & 5 & 6.40 & 2.966 & 2 & 9 & 3.50 & 7.00 & 9.00 \\
\hline
\end{tabular}

Table 2: Wilcoxon Signed Ranks Test.

\begin{tabular}{|c|c|c|c|c|c|}
\hline \multicolumn{6}{|c|}{ Wilcoxon Signed ranks Test } \\
\hline Ranks Group & & & $\mathbf{N}$ & Mean Rank & Sum of Ranks \\
\hline \multirow{4}{*}{1} & \multirow{4}{*}{ value of shade post - value of shade pre } & Negative Ranks & $5(a)$ & 3 & 15 \\
\hline & & Positive Ranks & $0(\mathrm{~b})$ & 0 & 0 \\
\hline & & Ties & $0(c)$ & & \\
\hline & & Total & 5 & & \\
\hline
\end{tabular}




\begin{tabular}{|c|c|c|c|c|c|}
\hline \multirow{4}{*}{2} & \multirow{4}{*}{ value of shade post - value of shade pre } & Negative Ranks & $5(a)$ & 3 & 15 \\
\hline & & Positive Ranks & 0 (b) & 0 & \\
\hline & & Ties & $0(\mathrm{c})$ & & \\
\hline & & Total & 5 & & \\
\hline \multirow{3}{*}{3} & \multirow{3}{*}{ value of shade post - value of shade pre } & Negative Ranks & $5(\mathrm{a})$ & 3 & 15 \\
\hline & & Positive Ranks & $0(\mathrm{~b})$ & 0 & 0 \\
\hline & & Ties & $0(\mathrm{c})$ & & \\
\hline \multicolumn{6}{|c|}{ a value of shade post $<$ value of shade pre } \\
\hline \multicolumn{6}{|c|}{ b value of shade post $>$ value of shade pre } \\
\hline \multicolumn{6}{|c|}{$\mathrm{c}$ value of shade post $=$ value of shade pre } \\
\hline \multicolumn{6}{|c|}{ Test Statistics(b) } \\
\hline group & & \multicolumn{4}{|c|}{ value of shade post - value of shade pre } \\
\hline \multirow{2}{*}{1} & $\mathrm{Z}$ & \multicolumn{4}{|c|}{$-2.032(\mathrm{a})$} \\
\hline & Asymp. Sig. (2-tailed) & \multicolumn{4}{|c|}{$.042^{*}$} \\
\hline \multirow{2}{*}{2} & $\mathrm{Z}$ & \multicolumn{4}{|c|}{$-2.041(a)$} \\
\hline & Asymp. Sig. (2-tailed) & \multicolumn{4}{|c|}{$.041^{*}$} \\
\hline \multirow{2}{*}{3} & $\mathrm{Z}$ & \multicolumn{4}{|c|}{$-2.032(\mathrm{a})$} \\
\hline & Asymp. Sig. (2-tailed) & \multicolumn{4}{|c|}{$.042^{*}$} \\
\hline \multicolumn{6}{|c|}{ a Based on positive ranks } \\
\hline \multicolumn{6}{|c|}{ b Wilcoxon Signed Ranks Test } \\
\hline
\end{tabular}

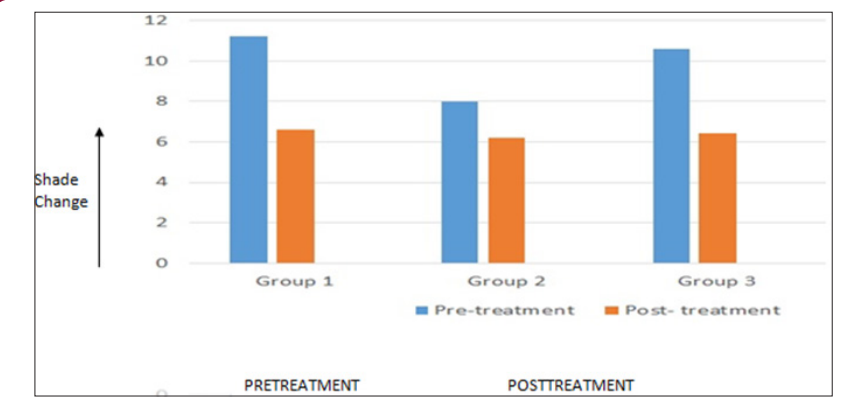

Figure 1: Values Were Obtained.

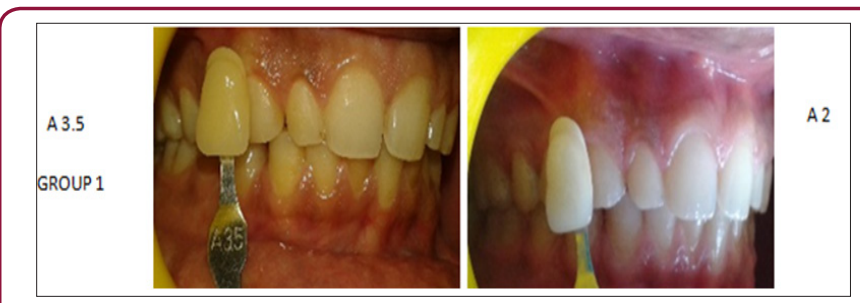

Figure 2: Bleaching Treatments, Baseline Numerical Shade Values.

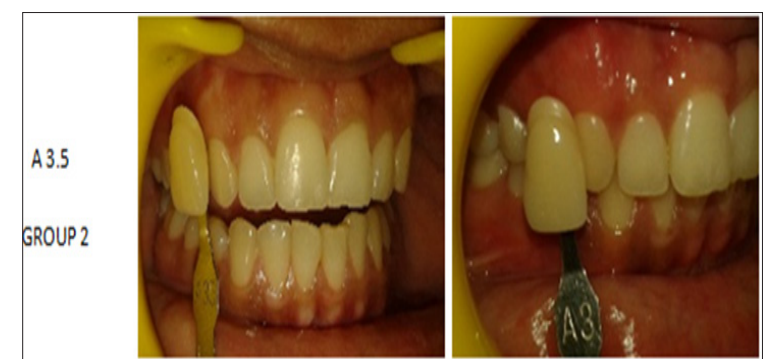

Figure 3: No Significant Difference Was Found.

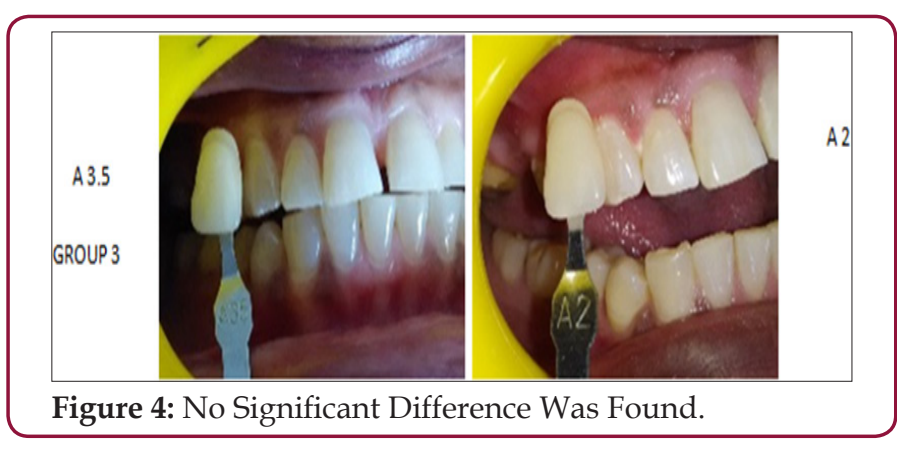

\section{Discussion}

In this study, whitening scores were evaluated to assess the validity of whitening toothpaste advertisement sclaiming that whitening will be observed after four weeks' use of whitening toothpaste. The whitening effects of the toothpastes were compared during this short period. Visual assessment with shade guides, computer analysis of digital images, colorimetry, and spectrophotometry can all be successfully used to measure the color change of teeth in longitudinal tooth bleaching studies [8]. Digital images offer an objective shade difference value, but the light and positioning of the subject must be standardized and a robust mathematical transformation algorithm must be used [9]. We used the Vitapan Classical shade guide ordered by value, considered a valid and reliable method for color assessment [10], and applied in previous investigations [1,11-13]. Other more sophisticated measurement systems are available $[10,17,18]$ but do not offer a more reliable accuracy, since different color measurements can be obtained for the same tooth according to the positioning of the probe tip of the device [14].The Vita shade visual assessment has 
previously been used successfully in many clinical studies [12-15]. It was therefore used in this study.

Previous studies have reported that whitening dentifrices produce a greater reduction and/or inhibition in extrinsic staining of natural teeth than standard commercial toothpaste formulations [16-18]. The active ingredients of toothpastes either include enzymes that dissolve pellicle proteins and inhibit staining, or contain chelating agents that have stain-dissolving properties. Alumina, dicalcium phosphate dihydrate, and silica are some of the abrasives that are included in whitening toothpastes [19]. In the present study, two whitening toothpastes were evaluated. Colgate visible white was used which consists of silica and polyphosphates that removes and prevent stains on teeth. The high cleaning silica in this toothpaste is similar to the abrasive materials used for cleaning and polishing teeth to remove surface stains. The polyphosphates are widely used to prevent surface staining due to plaque formation. Other toothpaste used was close up diamond attraction based on blue light technology.

It consists of sorbitol, hydrated silica, trisodium phosphate. Hydrated silica has been shown to have great cleaning and stainremovalability [20]. It has been suggested that another factor for whitening effect of toothpaste is $\mathrm{pH}$ Price. Reported that whitening toothpastes had a mean pH of 6.83 (range 4.22 to 8.35) [21]. The abrasive in toothpastes should ideally provide stain removal without causing wear of the tooth [22]. Lima. Reported that the enamel wear caused by these dentifrices still needs to be assessed before they are recommended for routine use [23-30]. In future studies, this criterion may be added for the evaluation of whitening toothpastes. In the present study Pola Office + was used which showed significant difference in pre and post treatment results. With SDI's new in-office system, Pola Office+, patients can have whiter and brighter teeth in less than one hour. The easy-to-handle, dual barrel and auto-mixing syringe system is economical and optimizes the workflow of the practice. In addition, the desensitizing agents and neutral pH make Pola Office + the ideal tooth-whitening material for vital and non-vital teeth. The active ingredient of Pola Office+ is $37.5 \%$ hydrogen peroxide and the gel rapidly releases peroxide ions upon contact with the tooth, enabling a shorter contact time compared with its competitors

\section{Conclusion}

Tooth-whitening toothpastes are effective for removal of superficial stains and for providing a whitening effect. Tooth whitening using minimally invasive techniques is enjoyable for the clinician and allows the patients to smile with confidence.

\section{References}

1. Claydon NCA, Moran J, Bosma M, Shirodaria S, AddyM, et al. (2004) Clinical study to compare the effectiveness of a test whitening toothpaste with commercial whitening toothpaste at inhibiting dental stain. Journal of ClinicalPeriodontolology 3(12): 1088-1091.

2. Pontefract H, Courtney M, Smith B, Newcombe RG, Addy M (2004) Development of methods to enhance extrinsic tooth discoloration for comparison of tooth pastes. Journal of Clinical Periodontology 31(1): $1-6$.
3. Soyman M (2002) Turkish Dental Association [Internet]. Istanbul: TDA. Dip Macunlar Kar plaptrmal Klinik Etkinlikleri. Accessed (2009 Sept 20) at: asp? ID=20. Turkish.

4. Sharif N, MacDonald E, Hughes J, Newcombe RG, Addy M (2000) The chemical stain removal properties of 'whitening' toothpaste products: studies in vitro. British Dental Journal 188(11): 620-624.

5. Lobene RR (1968) Effect of dentifrices on tooth stain with controlled brushing. Journal of the American Dental Association 77(4): 849-855.

6. Shaw L, Murray JJ (1977) A new index for measuring stain in clinical trials. Community Dentistry and Oral Epidemiology 5(3): 116-120.

7. Walsh TF, Rawlinson A, Wildgoose D, Marlow I, Haywood J, et al. (2005) Clinical evaluation of the stain removing ability of a whitening dentifrice and stain controlling system. Journal of Dentistry 33(5): 413-418.

8. Haywood VB, Heymann HO (1989) Night guard vital bleaching. Quintessence International 20(7): 173-176.

9. Mokhlis GR, Matis BA, Cochran MA, Eckert GJ. A clinical evaluation of carbamide peroxide and hydrogen peroxide whitening agents during daytime use. Journal of the American Dental Association 2000; 131(9): 1269-1277.

10. Kihn PW, Barnes DM, Romberg E, Peterson K (2000) A clinical evaluation of 10 percent vs 15 percent carbamide peroxide tooth-whitening agents. Journal of the American Dental Association 131(10): 1478-1484.

11. Godder B, Kaim JM, Scherer W, Bruck I, Hertz MB (1994) Evaluation of two at-home bleaching systems. Journal of Clinical Dentistry 5: 86-88.

12. Collins LZ, Maggio B, Liebman J, Blanck M, Lefort S, et al. (2004) Clinical evaluation of a novel whitening gel, containing $6 \%$ hydrogen peroxide and a standard fluoride toothpaste. Journal of Dentistry 32(1): 13-17.

13. Matheson JR, Cox TF, Baylor N, Joiner A, Patil R, Karad V, et al. (2004) Effect of toothpaste with natural calcium carbonate/ perlite on extrinsic tooth stain. International Dental Journal 545(1): 321-325.

14. Ayad F, Demarchi B, Khalaf A, Davies R, Ellwood R, Bradshaw B, et al. (1999) A six-week clinical efficacy study of a new dentifrice for the removal of extrinsic stain. Journal of Clinical Dentistry 10: 103-116.

15. Yankell SL, Shi X, Emling RC, Nelson BJ, Triol CW (1998) Laboratory evaluations of three dentifrices with polishing or brushing. Journal of Clinical Dentistry 9(3): 61-63.

16. Walsh TF, Rawlinson A, Wildgoose D, Marlow I, Haywood J, et al. (2005) Clinical evaluation of the stain removing ability of a whitening dentifrice and stain controlling system. Journal of Dentistry 33(5): 413-418.

17. Wulknitz P (1997) Cleaning power and abrasivity of European toothpastes. Advanced Dental Research 11(4): 576-579.

18. Price BTR, Sedarous M, Hiltz GS (2000) The pH of tooth whitening products. Journal of Canadian Dental Association 66(8): 421-426.

19. Meyers IA, McQueen MJ, Harbrow D, Seymour GJ (2000) The surface effect of dentifrices. Australian Dental Journal 45(2): 118-124.

20. Lima D, Silva A, Aguiar FHB, Liporoni PCS, Munin E, et al. (2008) In vitro assessment of the effectiveness of whitening dentifrices for the removal of extrinsic tooth stains. Brazilian Oral Research 22(2): 106-111.

21. Kowitz GM, Nathoo SA, Rustogi KN, Chmielewski MB, Liang IJ, et al. (1994) Clinical comparison of Colgate Platinum toothwhitening system and Rembrandt Gel Plus. Compendium of Continuing Education in Dentistry 17: 646-651.

22. Kleber CJ, Curtis J, Christina L, Milleman JL, Putt MS (1995) Effect of whitening toothpastes on stain removal and polish. Journal of Dental Research 74: 25.

23. Kleber CJ, Milleman JL, Curtis JP, Christina L, Putt MS (1996) Clinical study of whitening toothpastes for stain removal and enamel polish. Journal of Dental Research 75: 46. 
24. Nathoo S, Petrone ME, De Vizio W, Chaknis P, Volpe AR (2002) A six-week clinical study to compare the stain removing efficacy of three dentifrices. Journal of Clinical Dentistry 13(2): 91-94.

25. Sielski C, Berta RL, Petrone ME, Chaknis P, De Vizio W, et al. (2002) A study to assess the tooth-whitening efficacy of a new dentifrice formulation variant containing a special grade of silica: a six-week study on adults. Journal of Clinical Dentistry 13(2): 77-81.

26. Singh S, Mankodi S, Chaknis P, Petrone ME, De Vizio W, et al. (2002) The clinical efficacy of a new tooth whitening dentifrice formulation: a sixmonth study in adults. Journal of Clinical Dentistry 13(2): 89-90.

27. Sharif N, MacDonald E, Hughes J, New combe RG, Addy M (2000) The chemical stain removal properties of 'whitening' toothpaste products: studies in vitro. Brazilian Dental Journal 188(11): 620-624.
28. Watanabe MM, Rodrigues JA, Marchi GM, Ambrosano GM (2005) In vitro cariostatic effect of whitening toothpastes in human dental enamelmicro hardness evaluation. Quintessence International 36(6): 467-473.

29. Silva MF, Giniger MS, Zhang Y, Devizio W (2004) The effect of a triclosan/ copolymer/fluoride liquid dentifrice on interproximal enamel re mineralization and fluoride uptake. Journal of the American Dental Association 135(7): 1023-1029.

30. Forward GC, James AH, Barnett P, Jackson RJ (1997) Gum health product formulations: what is in them and why? Periodontology $200015: 32-39$.

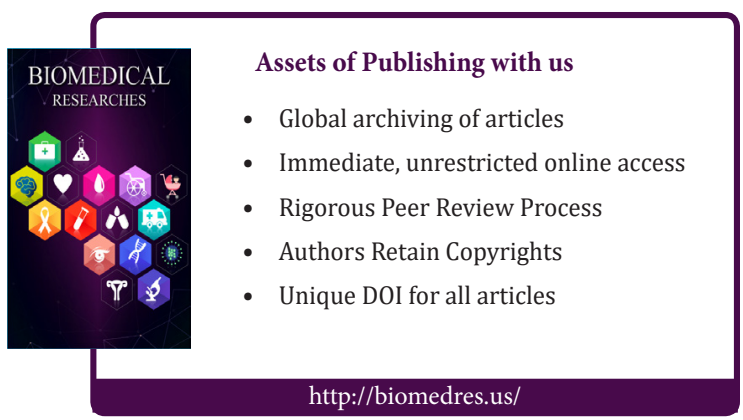

